\title{
A comparative study of whole body DWIBS MRI versus bone scan for evaluating skeletal metastases
}

\author{
Gandage SG, Kachewar SG, Aironi VD, Nagapurkar AD
}

Radio-diagnosis Department, RMC, PIMS(DU), Loni, Maharashtra, India

\section{RESEARCH}

Please cite this paper as: Gandage SG, Kachewar SG, Aironi VD, Nagapurkar AD and Pawar HJ. A comparative study of Whole Body DWIBS MRI versus Bone Scan for evaluating skeletal metastases. AMJ 2012, 5, 12, 619-622. http//dx.doi.org/10.4066/AMJ.2012.1500.

Corresponding Author:

Dr Sushil.G. Kachewar

Radio-diagnosis Department, Rural Medical

College, Pravara Institute of Medical Sciences

(DU), Loni, Maharashtra, INDIA-413 736

Email: sushilkachewar@hotmail.com

\section{Abstract}

\section{Background}

Skeletal metastases in oncology patients are identified by Bone scan and/Positron Emission Tomography (PET) scan. But developing countries in the world still lack adequate numbers of these imaging facilities.

Aims

Since Magnetic Resonance Imaging (MRI) is widely available as compared to bone scan or PET scan; a double blind study was undertaken to see if whole body imaging with MRI can give an idea of skeletal metastases.

\section{Method}

Diffusion weighted whole body Magnetic Resonance Imaging with background body signal suppression (DWIBS) was performed using 1.5 Tesla (T) MRI on histopathologically proven cases of carcinoma of breast within two months of mastectomy and followed up after a year of surgery. Similarly bone scan was also performed in these patients.

Results

DWIBS MRI demonstrated the presence and extent of bone metastases in 10 out of a total 18 patients included in study while bone scan could demonstrate them in only three cases. A highly significant difference between proportions of the skeletal metastases detected by whole body DWIBS-MRI than that by bone scan at one year follow-up. (i.e. $p<0.01$, $z=2.66$ ) was seen.

\section{Conclusion}

DWIBS MRI scores high in demonstrating skeletal metastases. Further comparative studies are necessary to evaluate if DWIBS can replace bone scan or PET scan.

\section{Key Words}

Skeletal Metastases; DWIBS MRI, Bone scan, PET scan, Cancer imaging, Onco Imaging, Whole Body Imaging

\section{What this study adds:}

1. The knowledge about the presence and extent of fresh or pre-existing skeletal metastases in oncology patients; significantly modifies management.

2. Like PET scan or bone scan, DWIBS MRI too can satisfactorily demonstrate skeletal metastases.

3. DWIBS MRI scores over bone scan; not only in demonstrating skeletal metastases but also in terms of wide scale availability of MRI and lack of radiation exposure in MRI.

\section{Background}

Malignancies in their diverse forms not only cause mortality and morbidity but also adversely affect the entire family of the afflicted. Prompt diagnosis, staging and identification of metastases at the earliest are the essential steps for timely management and a positive outcome.

Skeletal metastases are ruled out by whole body imaging that is primarily done either by bone scan or by PET scan. These imaging modalities are not widely available in developing countries and patients are frequently forced to wait. Also, there is radiation exposure to these patients who are already weakened by malignancies as well as by chemotherapy regimens. As MRI has the potential to detect metastatic lesions even before changes in bone metabolism make them detectable on bone scan; ${ }^{1}$ we decided to use a MRI-based whole body imaging technique called DWIBS to identify skeletal metastases and to compare it with results of bone scan. On bone scan skeletal metastases are demonstrated as areas of increased uptake; whereas on DWIBS MRI, these are seen as focal hypo intensities. ${ }^{1-5}$ 


\section{Method}

The study was carried out at the Rural Medical College, of Pravara Institute of Medical Sciences, Loni, Maharashtra, India, using 1.5 T MRI system. Permission of institutional ethical and research cell, and informed written consent from patients were obtained prior to study. Claustrophobic patients and those with general contra-indications for MRI study were excluded. All patients with mastectomy positive for breast carcinoma were included following surgery to assess for skeletal metastases first within three months of surgery and later at a 12 month interval. Bone scan was also done in these patients within a week of DWIBS MRI.

Table 1: Different parameters used for MRI DWIBS scan of the patients in this study

\begin{tabular}{|l|l|}
\hline Parameter & Value \\
\hline TR & $>5000 \mathrm{~ms}$ \\
\hline TE & $<70 \mathrm{~ms}$ \\
\hline EPI factors & 47 \\
\hline SENSE factor & 2 \\
\hline b value & $1000 \mathrm{sec} / \mathrm{mm}$ \\
\hline Slice thickness & $4 \mathrm{~mm}$ \\
\hline Breath hold & Not needed \\
\hline Total acquisition time & 10 minutes \\
\hline
\end{tabular}

Table 2: Comparison of whole body DWIBS MRI and Bone scan for evaluating for evaluation skeletal metastases

\begin{tabular}{|c|c|c|c|}
\hline \multirow[t]{3}{*}{ Modality } & \multirow{3}{*}{$\begin{array}{l}\text { Metas } \\
\text {-tasis }\end{array}$} & \multicolumn{2}{|l|}{ No. of cases } \\
\hline & & $\begin{array}{l}\text { Immediate } \\
\text { Post } \\
\text { operative }\end{array}$ & $\begin{array}{l}\text { One year follow- } \\
\text { up }\end{array}$ \\
\hline & & No. (\%) & No. (\%) \\
\hline \multirow{2}{*}{$\begin{array}{l}\text { Bone } \\
\text { scan }\end{array}$} & + & 0 & $3(16.67 \%)$ \\
\hline & - & $18(100 \%)$ & 15 (83.33\%) \\
\hline \multirow{2}{*}{$\begin{array}{l}\text { DWIBS } \\
\text { MRI }\end{array}$} & + & 0 & $10(55.56 \%)$ \\
\hline & - & $18(100 \%)$ & $8(44.44 \%)$ \\
\hline
\end{tabular}

[Value of $Z=2.66, p<0.01$, highly significant]

Parameters used for DWIBS protocol at our institute are shown in Table 1. Axial slices were reformatted to produce whole body image demonstrated with inversion of grey scale so that the final images resemble bone scan or PET scan-like images which are now well accepted by referring physicians and surgeons.

\section{Results}

DWIBS image in a healthy person (Figure 1) demonstrated normal hypo intense appearance in brain, central spinal canal, stomach, spleen and pelvis. ${ }^{1,3}$ But when skeletal metastases were present, prominent hypo intense areas were seen in the involved portion of skeleton. Tiny to large hypo intensities in lymph nodal regions in cases with nodal spread and hypo intensities in viscera like liver and spleen would be seen in cases with visceral spread.

Figure 1: DWIBS MRI image in a normal healthy volunteer

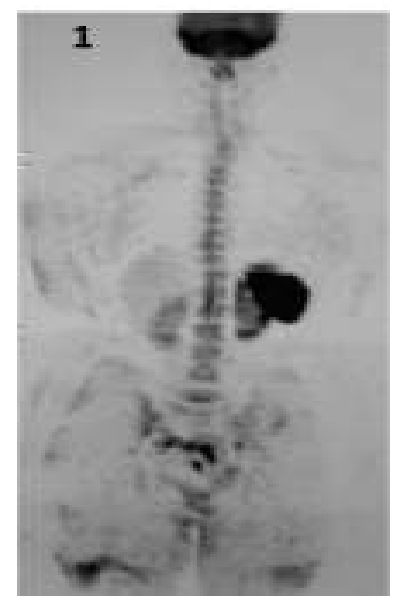

Figure 2: DWIBS image showing skeletal metastases (2a) not revealed by bone scan $(2 b)$ in both the thighs and the pelvis
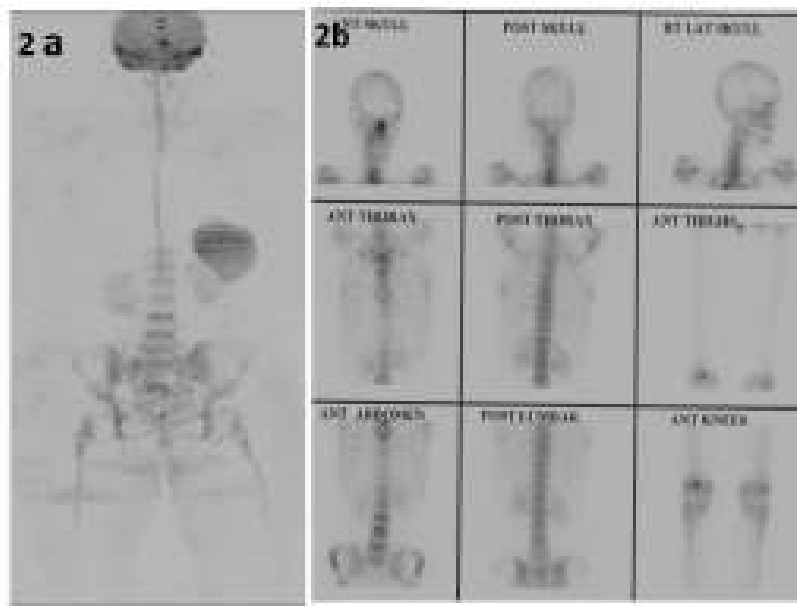

Out of the total of 18 patients referred for DWIBS Study, 10 showed skeletal metastases on DWIBS, and only three of these 10 showed skeletal metastases on bone scan as shown in Table 2. By applying $Z$ test of difference between two proportions there was a highly significant difference between proportions of skeletal metastasis detected by whole body DWIBS-MRI than that by bone scan at one year follow-up.(i.e. $p<0.01$ ). And there was no significant difference between proportions of skeletal metastasis at 
immediate post-operative period as seen on whole body DWIBS-MRI and that on bone scan (i.e. $p>0.05$ ).

Hence DWIBS was more sensitive that bone scan in detecting skeletal metastases. Representative and comparative images are shown in Figures $2 a$ and $2 b$ respectively.

\section{Discussion}

At present, oncoimaging for skeletal metastasis relies entirely on bone scan or PET scan for whole body imaging; although there are concerns about radiation hazards, economic constraints, scarce availability and prolonged waiting periods. DWIBS MRI can be an effective alternative especially where bone scan or PET scan is not available.

Areas with restricted diffusion occur in tumours due to high cellularity and many cellular membranes and; appears bright on diffusion weighted MRI. However, conventionally these images are printed with inversion of grey scale so that they resemble bone scan images as these are well accepted by treating doctors. ${ }^{2,3}$

Our initial results with DWIBS have been well accepted by the referring doctors. In fact when we analyse, compare and contrast various imaging techniques for evaluating skeletal metastases as shown in Table 3, we feel that DWIBS MRI is a viable alternative especially for developing countries where the availability of MRI facility is common than bone scan or PET scan.

Table 3: Comparative analyses of various imaging techniques for evaluating skeletal metastases

\begin{tabular}{|l|l|l|l|l|}
\hline $\begin{array}{l}\text { Sr } \\
\text { No }\end{array}$ & Criteria & $\begin{array}{l}\text { Bone } \\
\text { Scan }\end{array}$ & $\begin{array}{l}\text { PET } \\
\text { Scan }\end{array}$ & DWIBS MRI \\
\hline 1 & Availability & Less & Lesser & More \\
\hline 2 & $\begin{array}{l}\text { Prior } \\
\text { preparation }\end{array}$ & Needed & Needed & Unnecessary \\
\hline 3 & Scan Time & More & More & Less \\
\hline 4 & $\begin{array}{l}\text { Radiation } \\
\text { Exposure }\end{array}$ & Yes & Yes & No \\
\hline 5 & Repeatability & Limited & Limited & Unlimited \\
\hline 6 & $\begin{array}{l}\text { Usage in } \\
\text { Pregnant } \\
\text { patients }\end{array}$ & No & No & Unlimited \\
\hline 7 & $\begin{array}{l}\text { Usage in } \\
\text { Pediatric } \\
\text { patients }\end{array}$ & Limited & Limited & Unlimited \\
\hline 8 & Cost of study & More & More & Less \\
\hline
\end{tabular}

Limitations of DWIBS3 are that, abscesses can mimic malignancy. Poor anatomical details are noted. Normal non- pathological structures liver, GB, spleen, kidneys etc. also show up; hence basic T1, T2WI and STIR remain indispensable to act as an anatomical reference frame for the DWIBS images.

Discrepancy between PET scan and bone scan to detect bone metastases has been reported. ${ }^{5,6}$ Negative scintigraphy with positive magnetic resonance imaging in bone metastases has also been reported. ${ }^{7,8}$ Hence wide comparative studies between DWIBS, bone scan and PET scan are needed. ${ }^{9,10,11}$ DWIBS, an MRI similar to 18 F-FDG $\mathrm{PET} / \mathrm{CT}$ imaging, seems to be feasible in the detection of cancers; however it may be difficult to differentiate between the benign and malignant lesions. ${ }^{12}$

DWIBS is thus an upcoming MRI modality for cancer imaging wherever bone scan or PET scan is not available and cost is an issue. Moreover, DWIBS can be performed on state-ofthe-art MRI systems supplied by all major vendors.

The future prospects include comparative studies for the assessment of therapeutic response through Radiological and Nuclear Medicine Imaging Modalities, effective treatment of which is the final goal in managing skeletal metastases. $^{11,13}$

Our initial results prove that DWIBS is a good alternative for whole body imaging to assess metastases and help in staging of cancer patients. It is radiation free, widely available and cost efficient. Hence we suggest that it be used more often, although comparative studies with bone scan and PET scan would help in establishing statistical details about sensitivity and specificity of each modality as compared to DWIBS.

\section{Conclusion}

Due to economic constraints in developing nations, not all patients can afford the costly cancer treatment and imaging assessment. Advanced Imaging with PET-CT \& bone scan therefore remains a distant dream. DWIBS MRI promises a viable alternative to this necessity.

\section{References}

1. Takahara T, Imai Y, Yamashita T, Yasuda S, Nasu S, VanCauteren M. Diffusion weighted whole body imaging with background body signal suppression (DWIBS): technical improvement using free breathing, STIR and high resolution 3D display. Radiat Med 2004; 22:275-282.

2. Eustace S, Tello R, DeCarvalho V, Carey J, Wroblicka JT, Melhem ER et al. A comparison of whole-body turbo STIR MR imaging and planar 99mTc-methylene 
diphosphonate scintigraphy in the examination of patients with suspected skeletal metastases. AJR Am J Roentgenol. 1997 Dec;169(6):1655-61.

3. Kwee TC, Takahara T, Ochiai R, Nievelstein, Luijten $P R$. Diffusion-weighted whole-body imaging with background body signal suppression (DWIBS): features and potential applications in oncology. Eur Radiol. 2008 Sep;18(9):1937-52

4. Bammer R. Basic principles of diffusion-weighted imaging. Eur J Radiol. 2003 Mar;45(3):169-84.

5. Kao CH, Hsieh JF, Tsai SC, Ho YJ, Yen RF. Comparison and discrepancy of 18F-2-deoxyglucose positron emission tomography and Tc-99m MDP bone scan to detect bone metastases. Anticancer Res. 2000 MayJun;20(3B):2189-92.

6. Franzius $C$, Sciuk J, Daldrup-Link HE, Jürgens $H$, Schober O. FDG-PET for detection of osseous metastases from malignant primary bone tumours: comparison with bone scintigraphy. Eur J Nucl Med. 2000 Sep;27(9):1305-11.

7. Kattapuram SV, Khurana JS, Scott JA, el-Khoury GY. Negative scintigraphy with positive magnetic resonance imaging in bone metastases. Skeletal Radiol. 1990;19(2):113-6.

8. Evans AJ, Robertson JF. Magnetic resonance imaging versus radionuclide scintigraphy for screening in bone metastases. Clin Radiol. 2000 Aug;55(8):653

9. Daldrup-Link HE, Franzius C, Link TM, Laukamp D, Sciuk J, Jürgens $\mathrm{H}$, et al. Whole-body MR imaging for detection of bone metastases in children and young adults: comparison with skeletal scintigraphy and FDG PET. AJR Am J Roentgenol. 2001 Jul;177(1):229-36.

10. Dickinson F, Liddicoat A, Dhingsa R, Finlay D. Magnetic resonance imaging versus radionuclide scintigraphy for screening in bone metastases. Clin Radiol. 2000 Aug;55(8):653.

11. Kachewar SG. Using DWIBS MRI technique as an alternative to bone scan or PET scan for whole-body imaging in oncology patients. Acta Radiol 2011; 52: 788.

12. Komori T, Narabayashi I, Matsumura K, Aga F, Matsuki M. ${ }^{18}$ F-FDG PET/CT versus body diffusionweighted MRI for detection of malignant lesions. J Nucl Med 2006; 47:483.

13. Vassiliou V, Andreopoulos DY, Frangos SZ, Tselis NX, Giannopoulou EJ, Lutz S. Bone metastases: Assessment of therapeutic response through Radiological and Nuclear Medicine Imaging Modalities. Clin Oncol (R Coll Radiol). 2011 Nov;23(9):632-45.

\section{ACKNOWLEDGEMENTS}

To all the patients for their kind co-operation and active participation.

\section{PEER REVIEW}

Not commissioned. Externally peer reviewed

\section{CONFLICTS OF INTEREST}

The authors declare that they have no competing interests.

\section{FUNDING}

This research was funded by Research grant of Pravara Institue of Medical Scienecs, Deemed University, Loni, Maharashtra, India

\section{ETHICS COMMITTEE APPROVAL}

The Ethical and Research Committee of Pravara Institue of Medical Scienecs, Deemed University, Loni, Maharashtra, India approved this study and its budget via official letter having reference No. PIMS/PMT/RC/2011/100; dated: 9-52011. Philips Health Care India Ltd provided the technical support for this research. 